\title{
Joint Functional Focus of Models of Civil Liability for Damage Inflicted on Patients
}

\author{
Volodymyr Prymak ${ }^{1, *}$, Olga Koreniuk ${ }^{2}$ and Tatiana Poharchenko ${ }^{2}$
}

${ }^{1}$ Department of International Private and Comparative Law, Academician F.H. Burchak Scientific and
Research Institute of Private Law and Entrepreneurship of the National Academy of Legal Sciences of
Ukraine, Kyiv, Ukraine
${ }^{2}$ Department of International, Civil and Commercial Law, Kyiv National University of Trade and Economics,
Kyiv, Ukraine

Abstract: One of the key areas of legal regulation of any aspect of public life (especially when it comes to personal moral rights inalienable from a person, including those that ensure the person's physical existence and reflect the human dignity inherent in every individual) is the establishment of legal guarantees for the observance and protection of subjective rights belonging to a person. The purpose of this study is to determine the centripetal (in value and functional terms) trends in the development and application of similar legal models and means of legal regulation of relations arising from harm inflicted on patients. It was concluded on the inevitability of the intensification of the world, and European, in particular, tendencies regarding the diverse use by national legal systems of similar functional legal instruments for compensation for property and moral damage in order to ensure effective protection of personal nonproperty and property rights of patients and related persons. Therewith, the identity of a certain national legal mechanism will be determined mainly by the orientation of the legal policy of a particular state towards the top-priority implementation of certain characteristics of compensation and proactive, preventive (which, in the context under consideration, appears as a guarantee for the observance of the rights of patients and the performance of obligations by the providers of medical services) functions of civil liability.

Keywords: Medical services, compensation for property and moral (non-pecuniary) damage, fault, insurance, legal regulation.

\section{INTRODUCTION}

One of the key areas of legal regulation of any aspect of public life (especially when it comes to personal moral rights inalienable from a person, including those that ensure the person's physical existence and reflect the human dignity inherent in every individual) is the establishment of legal guarantees for the observance and protection of subjective rights belonging to a person.

Among these guarantees in the field of healthcare in general and in medical practice in particular, the leading guarantee is the civil liability of medical care professionals (providers) for damage caused by their actions or inaction to patients and sometimes to persons related to the latter (in this regard, the literature rightly states that it is a civil and criminal law that give the complete answer to the question of encouraging the proper conduct of medical staff in the performance of their duties) (Phillips et al. 2019).

Potentially, any person - either a patient seeking medical care or his or her related individuals (Palmer

*Address correspondence to this author at the Academician F.H. Burchak Scientific and Research Institute of Private Law and Entrepreneurship of the National Academy of Legal Sciences of Ukraine, Kyiv, Ukraine;

Tel: (044) 25614 57, E-mail: vprymak@nuos.pro
2015) - may be adversely affected by the improper organisation of professional activities for the provision of medical services, just as harm can be inflicted not only by healthcare professionals but also by government officials (Bączyk-Rozwadowska 2011) (for example, in the absence of the necessary control over the compliance of medical institutions or private practitioners with the established licensing conditions). In theoretical terms, this refers to the need to ensure the implementation of the fundamental principles of freedom and security, justice and efficiency, formalised in the Principles, definitions and model rules of European private law (Farmonovich 2019), in the legal regulation of both purely positive and related security relations in the field of healthcare.

At the same time, in the conventional aspect of human rights and fundamental freedoms, the case-law of the European Court of Human Rights inevitably comes to the forefront of protecting the rights of patients and their relatives (Tatu 2018). This, in turn, draws the attention of legal scientists primarily to the study of ways and forms of the fulfilment of the functional potential of civil liability (Bagińska 2015), which, incidentally, coincides with the substantive features of an effective remedy formulated by the European Court of Human Rights (Guide on Article 13... 2020) (since each time the legislator, the bearers 
of subjective rights and obligations, as well as the subjects of law enforcement will reckon with the preventive and/or compensatory influence of a certain instrument of legal pressure).

Admittedly, the objective definition of the laws of legal regulation of various relations in the field of healthcare (medical care in particular) cannot but lead to the development of counter or cross vectors in the evolutionary development of relevant components of national legal systems, sometimes belonging to very different historical sources and traditions of legal families. Therefore, the purpose of this study is to determine, relatively speaking, the centripetal (in value and function) trends in the development and application of similar legal models and means of legal regulation of relations arising from harm inflicted on patients.

\section{MATERIALS AND METHODS}

To start with, it is worth noting two methodologically important aspects. Firstly, when conducting this kind of research, one should be alert to the interdisciplinary approach (Sommer et al. 2016), as it will inevitably contribute to the effective balancing of private and public interests, as well as the interrelated interests of patients, members of the legal community and healthcare professionals. From this standpoint, for example, the emphasis made in Paragraph 6 of the Statement on Medical Responsibility Reform adopted by the World Medical Association (WMA) on the need to be aware of the difference between harm caused by medical negligence and the adverse outcomes that occurred during medical care and treatment, but not through the doctor's fault. In the latter case, according to the WMA, each country must determine whether to cover the damages for the patient and if so, from what source. In this case, the availability of appropriate solidarity funds will follow from the economic conditions of a particular country (WMA Statement on Medical Liability Reform 2015). Notably, the outlined approach is quite successfully implemented in a number of European countries (Sweden, France, Belgium). Therewith, the stability of the medical industry is ensured mainly by the transfer of the financial burden of strict liability "on the shoulders" of insurance funds. This, however, does not deny the possibility of judicial protection of patients - especially in the case of harm to them through the gross fault of the medical services provider (Watson and Kottenhagen 2018).

Secondly, it is necessary to carefully assess the codification efforts of legislators of individual states towards positive consolidation of special rules, which appear as a result of long-term application of fully justified, general plan provisions, which traditionally regulate contractual and non-contractual liability or regulatory contractual relations on the provision of medical services. In this context, it is necessary to mention the provisions of Articles $630 \mathrm{a}-630 \mathrm{~h}$ of the German Civil Code (German civil code 2002) (hereinafter referred to as "the GCC") concerning the contract for the provision of medical services, in case of violation of which Articles 276 and 280 of the GCC on responsibility for violation of duty on the basis of fault. Accordingly, in the absence of a contractual relationship, the protection of the patient's rights will be fully ensured in tortious obligations (Article 823 of the GCC). The opposite trend towards legislative efforts can be observed in the civil law of the People's Republic of China (PRC) (both in accordance with the 2009 Tort Liability Act (The Tort Liability Law... 2009) and the provisions of the 2020 Civil Code of China), where the provisions on civil liability for medical damage are specified in the rules on tortious liability (Chapter 7 "Liability for Medical Damage" of the above Law and the eponymous Chapter 6 of Section 7 "Tort Liability" of the Civil Code of the PRC). The positive responsibilities of healthcare providers are also defined within the institution of non-contractual liability.

According to the aforementioned legal acts, China's tort law remains committed to responsibility for fault. In particular, Article 1222 of the Civil Code of the PRC establishes the presumption of the fault of a medical institution if the patient during the diagnosis or treatment suffers damage due to the following circumstances (actions of medical staff): (1) violation of regulations and administrative acts on medical activities; (2) concealment or refusal to provide medical records related to the dispute; (3) loss, forgery, or illegal destruction of medical records (Conk 2020). Thus, despite the stability and effectiveness of legal regulation through the general rules of contractual and non-contractual liability, codification activities, admittedly, greatly contribute to the establishment of legal certainty, accumulating the approaches developed by the judicial practice. Thus, by specifying the responsibilities of the medical service providers, the German legislator clarified the factual grounds of these providers' liability, which in the most generalised form can be reduced to three main grounds: 1) commission of medical errors despite the full possibilities to prevent the risk of adverse consequences for the patient; 2) failure to provide the patient with the necessary information (upon obtaining consent for medical intervention or in connection with the documentation of 
the latter); 3) violation of the qualification requirements for medical staff.

Therewith, medical errors, according to Article $630 \mathrm{a}$ of the GCC are established through the criterion of violation of generally accepted medical standards that exist at the time of treatment. At the same time, the literature distinguishes between, among other things, organisational or administrative errors (such as violations of sanitary and hygienic norms, responsibilities for the provision of medicines or safety of equipment) and the actual medical errors diagnostic and therapeutic. In addition, breaches of patient information responsibilities can be divided into breaches of medical and economic information about treatment (Sommer et al. 2016). Admittedly, any such specification, on the one hand, encourages medical services providers to make appropriate efforts in each segment of the activity associated with the observance of patients' rights, and on the other hand, creates additional guarantees for patients to receive compensatory protection in case of violation of their rights.

Notably, the essentially identical interrelation between regulatory and protective legal relations, preventive and compensatory functions of civil liability of professionals in the field of medicine can also be traced in Anglo-American law. To substantiate a claim for damages for a violation of a patient's rights, the plaintiff in the US's state of Georgia must prove: a) the imposition of a legal obligation on the defendant to exercise due care and caution or conformity to a certain standard of conduct designed to protect others; b) the fact of violation of this standard; c) the existence of an interrelation between the said violation and damage to the patient's health; d) the occurrence of damage on the part of the plaintiff as a result of the violation committed by the defendant. In this case, due care and caution are considered as the degree of reasonable caution, prudence, which is analogous or similar circumstances is exercised by an ordinary person, and the appropriate standard of care will be the one that under the same conditions and similar circumstances is generally followed by medical professionals (Daller and Daller 2019).

\section{RESULTS AND DISCUSSION}

\section{Characteristics of Individual Elements of The Mechanism of Civil Liability}

Based on the above, the individual characteristics of a national mechanism of compensation for damage to patients are determined mainly by balancing its individual elements (placed in accordance with their specific gravity and temporal dimension of professional legal activity in the area under study):

1. Application of measures of contractual or noncontractual liability (Bennett et al. 2020), the involvement of tools of social (public) or private insurance.

2. Attitude towards fault as grounds (condition) for liability of a medical services provider - in the sense of the need to prove a certain degree of such fault, the possibility of refuting the presumption of fault, or the introduction of strict (regardless of the presence or absence of fault of the obligor) liability.

3. General formalisation (violation of the standard of reasonable care) or clear definition of the criteria of illegality (regarding compliance with documented treatment standards, clinical protocols, obtaining informed patient consent, etc.).

4. Provision of legal significance to the specific correlations of causality that have conditioned the individually determined nature of the damage caused to the patient. However, in compensating for non-pecuniary damage caused by the improper provision of medical care, causality sometimes recedes into the background - a case in point would be such a situation as the award of compensation for lost opportunities (regarding cure or survival) (Winiger et al. 2011). Similarly, in the context of causality, European legal systems usually deal with conflicts arising from obligations with a passive plurality of persons. At the same time, it is necessary to take into account significant differences in establishing causality between the harm inflicted on the patient, violation of his or her rights, and two main types of illegal actions of medical staff (Hyslop 2015) - medical errors upon medical intervention and abuse in informing the patient about the nature and the consequences of such an intervention.

5. Introduction of independent approaches to compensation for damage caused in connection with the provision of certain types of medical services or given the nature of the negative consequences of medical intervention for human 
health, as well as considering the special legal separation from the latter of individual manifestations of the negative influence of the very fact of violation of the victim's rights on his or her non-property sphere. Given these factors, the grounds for civil liability can be determined as causing property and moral damage, and violation of the general right of the person as such (Dostál 2011). Admittedly, in this area, one cannot ignore the desire to individualise certain types of moral harm, such as, for instance, "pain and suffering" and "mental harm", which differ in the criterion of formalising the medical consequences of the latter in the form of a certain diagnosis (Palmer 2015).

6. Determination of the probable range of victims as a result of unsuccessful medical intervention and specifying the subjects of responsibility (in terms of their separation from the direct inflictors of harm).

7. The division of procedural responsibilities between the parties in the evidentiary activity and the prevailing standard of proving the conditions of liability. Thus, in establishing causal links between the violation of the rules of medical care and the damage caused, Italian courts focus on the logically predictable result of wrongful conduct, which is established according to the standard of "superiority of evidence" and the criterion "more likely than not" (Comandé 2014). In most European countries - for example, in the Czech Republic - the burden of proof is somewhat different depending on the type (basis) of liability. In the case of compensation for property and non-pecuniary damage, the plaintiff proves the existence of objective conditions of liability - an illegal act, the amount of damage, the causality between the two previously mentioned conditions. At the same time, there is a presumption of fault except for cases where the law introduces strict liability. When the legislator aims to protect the individual as such, the plaintiff proves: the defendant's breach of duty, which could lead to the suppression of the personal rights of the victim; commission of an actual encroachment on the latter; the correlation between the two previous conditions. Moreover, this type of liability does not take into account the fault of the obligor (Dostál 2011).
8. Correlation of related tools of criminal, administrative, and civil justice, mechanisms for out-of-court settlement (primarily within the organisational forms of constant interaction of patients' representatives and administrations of medical institutions, the establishment of special compensation funds in case of damage not subject to tort liability or to a sufficient compensation through insurance payments (Koch 2013)), expert and disciplinary activities of professional medical associations, etc.

\section{Common Principles of Legal Regulation in American and European Legislation}

Thus, despite the significant differences between the national legal systems belonging to different legal families, the common values rooted in them give rise to increasingly pronounced tendencies to further convergence of approaches and individual models implemented in the field of compensation for property and non-pecuniary losses caused to consumers. Instead, the most significant differences that continue to exist here are mainly conditioned by sociopsychological and socio-economic factors, such as national mentality (entrepreneurship or paternalism), the institutional capacity of the professional legal environment, and the overall income of the participants. Not the least role is played by the specific features of the construction and functioning of the justice system (there is a good reason that due to the sometimesexorbitant amounts of compensation, public attention is repeatedly chained to the North American model of jury trial).

Among other things, this is why the number of claims for damages caused to patients in the European area and the number of related court costs cannot be compared with similar indicators, as demonstrated by legal practice in this category of cases in the United States. It is also not surprising that the issues on the correctness and even constitutionality of the legislative establishment of the upper limits of compensation awarded to injured patients (especially in terms of compensation for non-pecuniary damage (Martin et al. 2020) or compensation for punitive damages, which are very sensitive for the American specialists, are not a priority for their European colleagues.

However, even in the existing differences, it is easy to find common ground in legal regulation. Suffice it to mention the prevalence of the "Anglo-American emphasis" on the need to implement not only the 
compensatory but also the preventive function of tort law, which is no less important from the social standpoint (Sharkey 2005). As a result, there is a paradox - the current offensive of strict liability of medical care providers across the European countries, which can be observed in the last two decades, is entering into obvious dissonance with the resistance of the American supporters of traditional tort law, who advocate the greatest possible consideration of the criteria of good faith (admittedly, in the European understanding of this principle), defined through the lens of compliance or violation of due care and caution by the medical care provider upon the provision of medical care, specified in the given life situation standard. On the other hand, for European approaches, the use of fault as a criterion for determining the amount of civil liability is extremely rare - however, without this, the very idea of punitive damages loses its grounds.

In this way, the American model absorbs elements of conventional continental liability for fault, and the European model - strict liability, which is usually considered as a hallmark of the Anglo-American (albeit mostly contractual) law. Imitation of overseas patterns can be seen in the steady increase in the amount of compensation and the expansion of the scope of subjects entitled to receive them. This scope already includes not only the patients themselves, people in the vegetative state and new-borns, regardless of their life expectancy but also members of their families and sometimes even visitors to patients in medical care facilities.

In general, it is common for European legal families to be extremely careful about establishing a causal link between the damage to the patient's health (it's component) and the factors that caused it. Adequately equivalent approach common in this area minimises the possibility of imposing an unfair burden on medical professionals, taking into account the individual characteristics and behaviour of the patient, the expected dynamics of his or her health, the need to proportionally distribute the risks of an unfavourable result of a subsequent medical intervention between several performers at once involved in the provision of medical services. One cannot ignore the unity in the definition of the subject of responsibility, which is most often determined directly by the medical institution in the actual provision of services by its employees.

Among the most significant changes in the opinions of scholars and approaches of national legal science of different countries to the determination of the grounds for compensation for moral damage caused in the field of healthcare, is the gradual convergence of the two complementary vectors of legal regulation. On the one hand, this refers to focus on the award of appropriate compensation in connection with the actual physical or mental losses, which is traditional for tort law, and on the other hand, this also refers to an increasingly noticeable tendency, which occurred due to the implicit reception of the positions of the European Court of Human Rights, to also ensure the protection of the general human right (for example, in case of violation of the patient's right to provide effective informed consent to medical intervention) (Rijnhout and Emaus 2014). It should be recognised that the development of this approach opens up very broad prospects for providing compensatory protection to a much larger number of patients, their family members, and close relatives. For example, the interests of the latter group come to the fore in the event of death, prolonged comatose, autonomic, or other similar condition.

And while in some countries (e.g., the Netherlands) the outlined trend is only paving its way, in others it has already gained a fairly clear legal framework (BączykRozwadowska and 2011) and indisputable doctrinal recognition. Thus, in Poland, the combined use of both grounds for compensation for non-pecuniary damage in the field of healthcare - the recovery of compensation for pain and suffering caused by damage to health, along with compensation for infringement of the dignity, private sphere, and personal autonomy of the patient (moreover, regardless of the conscientiousness and efficiency revealed during the medical intervention on the part of the personnel of the medical institution) (Bagińska 2015).

In this case, the immediate grounds for compensation for moral damage may be diagnostic errors caused by negligent bodily injury, violation of the obligation to obtain the informed consent of the patient, infection with nosocomial infections, birth injuries, etc. Neither the patient's level of awareness of the circumstances of the case nor his or her ability to feel pain or individual sensitivity is significant here. At the same time, the reverse proportion in the awarding of compensation is clearly traced, where the younger the victim is in age, including in case of a claim on behalf of a new-born child by parents who, after its death, appear in court as heirs of the deceased person, the higher is the compensation amount awarded (Bagińska 2015). 


\section{Analysis of Insurance Mechanisms}

Insurance relations are extremely closely connected with the relations of civil liability (first of all, tort, and in some cases also contractual relations). Among other things, it is here that the main legal framework for the implementation of enhanced - independent from the obligor's fault - compensatory protection of the victim is developed (Schäfer and Müller-Langer 2008). Given the above-mentioned definition of property consequences of violations of patients' rights, alternative guarantees of protection of the interests of both injured consumers of medical services and providers of the latter - medical institutions and private medical practitioners - are gaining great importance.

Accordingly, the first case refers to the coverage of the risks of hypothetical harm to the patient's health by obliging the private or public (social insurance) insurance funds to make direct payments in favour of the victim in case of an insured event. Depending on the purpose, such payments will be directed either to the victim personally (in terms of levelling the signs of a decrease in working capacity and the possibility of earning income) or directly to other professionals who will provide "replacement" services related to the elimination of the negative consequences of previous treatment.

Instead, the second case refers to the classic type of insurance of civil liability of the performer (provider) of medical services, which arises based on a special tort or breach of contract. Moreover, the payment of insurance indemnity in such a situation does not preclude the possibility of presenting two relatively independent property claims: a) to pay compensation for losses not covered by insurance indemnity because outside the insurance relationship will always be a possibility of obtaining additional compensation in court, which will reimburse losses not covered by insurance payments; b) concerning compensation for moral (non-pecuniary) damage caused not by pain and suffering but by the fact of violation of personal nonproperty human rights to his or her physical integrity and inviolability (encroachment on human dignity, personal autonomy, and unlawful interference with private life).

Finally, the interaction of private and public components of both of the above and interconnected insurance mechanisms is not excluded. Then, given the obligation of social insurance or professional liability insurance, private law elements will play the role of a kind of subsidiary guarantee of protection of the interests of both patients and healthcare providers. Here two more "cross" issues come to the fore - one is common to tort and insurance law, while the other allegedly purely insurance-related. The scope of the first "cross" issue lies with the general boundaries of compensation, which is paid in favour of the victim first of all, upon compensation for moral damage, since the principle of full compensation for negative property consequences remains almost inviolable. Certain exceptions can be found only in the areas of medical care related to the provision of luxury services. At the same time, the second "cross" issue relates to the stability of the defined segment of the insurance market and the basis of tort law - liability for fault, and in addition, relates to the principles of good faith and fairness. Practical consideration of all the outlined factors is embodied in the legislative definition of the grounds for subrogation (in the field of insurance of property interests of the patient) or filing a recourse claim (in the field of liability insurance of the medical care provider).

In this regard, one inevitably has to return to the question of replacing liability for fault or negligence (in its Anglo-American interpretation as a basis for tort) with the so-called strict liability, which describes the subjective side of the behaviour of a professional in medicine or their compliance with the criterion of due care and caution in understanding the correspondence of actions of the medical personnel with the standards of provision of certain types of services lose their exceptional importance as usually indispensable prerequisites for the emergence of obligations to compensate for harm. The fact is that in such circumstances, both subrogation and recourse can be substantiated only by the same traditional arguments of reproach for improper performance of professional duty if there is an objective possibility to prevent harm. And here it seems fair to return to the origins of "medical responsibility", which was originally associated, as a rule, exclusively with the gross fault of the medical staff. From this standpoint, in the Czech Republic, the possibility of recourse by the national insurer (public insurance) is quite fairly associated with the discovery of the fact of intentional harm to the patient (Dostál 2011).

\section{CONCLUSION}

Based on the above, one can conclude ton the inevitability of the intensification of the world, and European, in particular, tendencies regarding the 
diverse use by national legal systems of similar functional legal instruments for compensation for property and moral damage in order to ensure effective protection of personal non-property and property rights of patients and related persons. Therewith, the identity of a national legal mechanism will be determined mainly by the orientation of the legal policy of a particular state towards the priority of implementing certain characteristics of compensation and proactive, preventive (which in this context appears as ensuring the observance of patients' rights and responsibilities of medical care providers) functions of civil liability. Despite the significant differences between the national legal systems belonging to different legal families, the common values rooted in them give rise to increasingly pronounced trends towards further convergence, approaches, and individual models implemented in the field of compensation of property and non-pecuniary damage inflicted on patients as consumers of medical services.

\section{REFERENCES}

Bączyk-Rozwadowska, Kinga. 2011. "Medical malpractice and compensation in Poland". Chicago-Kent Law Review 86(3): 1220-1221.

Bagińska, Ewa. 2015. "Poland: Developments in personal injury law in Poland: Shaping the compensatory function of tort law". Journal of Civil Law Studies 8: 333-336.

Bennett, Georgia, Meng-Wong Taing, Laetitia Hattingh and Adam La Caze. 2020. "Pharmacists' perceived responsibility for patient care when there is a risk of misadventure: A qualitative study". International Journal of Pharmacy Practice 28(6): 599-607. https://doi.org/10.1111/ijpp.12580

Comandé, Giovanni. 2014. "Italy". In: H. Nys (Ed.), International Encyclopaedia of Laws: Medical Law. Alphen aan den Rijn: Kluwer Law International.

Conk, George. 2020. "Translation: Tort liability - section 7 - Civil Code of the people's Republic of China". Fordham Law Legal Studies Research, 3624921. https://doi.org/10.2139/ssrn.3624921

Daller, Morton and Nicholas Daller. 2019. Tort law desk reference: A fiftystate compendium. New York: Wolters Kluwer.

Dostál, Ondrej. 2011. "Medical liability in Czech Republic". In: B.A. Koch (Ed.), Medical Liability in Europe: A Comparison of Selected Jurisdictions. Berlin: Walter de Gruyter. https://doi.org/10.1515/9783110260168.97

Farmonovich, Fayziyev. 2019. "Medical law and features of legal relations arising in the provision of medical services". International Journal of Pharmaceutical Research 11(3): 1197-1200.
German Civil Code. 2002. Retrieved November 15, 2020. (https://www.gesetze-iminternet.de/englisch_bgb/englisch_bgb.html\#p0761)

Guide on Article 13 of the Convention - Right to an effective remedy. $2020 . \quad$ (https://www.echr.coe.int/Documents/Guide_Art 13_ENG.pdf)

Hyslop, Edward lan. 2015. European causation in tort law: A comparative study with emphasis on medical law in the United Kingdom, Germany and France and Luxembourg: a thesis submitted for a degree of $\mathrm{PhD}$ in law. Esch-Sur-Alzette: University of Luxembourg.

Koch, Bernhard. 2013. "Medical malpractice in Austria". In: K. Oliphant, R.W. Wright (Eds.), Medical Malpractice and Compensation in Global Perspective. Berlin; Boston: Walter de Gruyter.

Martin, Ellen, Jeannette Kraft, Rochelle Wilder and Helen Bryant. 2020 "Safeguarding children in trauma and orthopaedics". Orthopaedics and Trauma 34(6): 379-389. https://doi.org/10.1016/j.mporth.2020.09.008

Palmer, Vernon. 2015. The recovery of non-pecuniary loss in European contract law. Cambridge: Cambridge University Press. https://doi.org/10.1017/CBO9781316162378

Phillips, Andelka, Thana C. de Campos and Jonathan Herring. 2019. Philosophical foundations of medical law. Oxford: Oxford University Press. https://doi.org/10.1093/oso/9780198796558.001.0001

Rijnhout, Rianka and Jessy Emaus. 2014. "Damages in wrongful death cases in the light of European human rights law: towards a rightsbased approach to the law of damages". Utrecht Law Review 10(3): 91-106 https://doi.org/10.18352/ulr.286

Schäfer, Hans-Bernd and Frank Müller-Langer. 2008. "Strict liability versus negligence". German Working Papers in Law and Economics 5: 1-33 https://doi.org/10.2139/ssrn.2062787

Sharkey, Catherine. 2005. "Unintended consequences of medical malpractice". New York University Law Review 80(2): 399-405.

Sommer, Steffen, Rene Geissler, Ulrike Stampfl, Maya B Wolf, Boris Alexis Radeleff, Goetz Richter, Hans-Ulrich Kauczor, Philippe Pereira and Christof Sommer. 2016. "Medical liability and patient law in Germany: Main features with particular focus on treatments in the field of interventional radiology". RöFo Fortschritte auf dem Gebiet der Röntgenstrahlen und der bildgebenden Verfahren 188(4): 353-358. https://doi.org/10.1055/s-0041-108198

Tatu, Daniela. 2018. Medical negligence: In the case-law of the European Court of Human Rights. Milan: Key Editore.

The tort liability law of the people's Republic of China. 2009 (http://www.npc.gov.cn/zgrdw/englishnpc/Law/201102/16/content_1620761.htm)

Watson, Kenneth, Rob Kottenhagen. 2018. "Patients' rights, medical error and harmonisation of compensation mechanisms in Europe". European Journal of Health Law 25: 1-23. https://doi.org/10.1163/15718093-12460348

Winiger, Bénédict, Koziol, Helmut, Bernhard Koch and Reinhard Zimmermann. 2011. Digest of European tort law. Vol. 2: Essential cases on damage. Berlin, Boston: Walter de Gruyter. https://doi.org/10.1515/9783110248494

WMA Statement on medical liability reform. 2015. Retrieved November 15, 2020: (https://www.wma.net/policies-post/wma-statement-onmedical-liability-reform/

Received on 01-01-2021

Accepted on 25-01-2021

Published on 02-02-2021

\section{DOI: https://doi.org/10.6000/1929-4409.2021.10.47}

(c) 2021 Prymak et al.; Licensee Lifescience Global.

This is an open access article licensed under the terms of the Creative Commons Attribution Non-Commercial License (http://creativecommons.org/licenses/by-nc/3.0/) which permits unrestricted, non-commercial use, distribution and reproduction in any medium, provided the work is properly cited. 